\title{
Waist to stature (height) ratio and clustering of metabolic syndrome components in Chilean children and adolescents
}

\begin{abstract}
Obesity in children and adolescents is associated with increased risk of presenting metabolic syndrome (MS) and cardiovascular risk in the long term. Waist to stature (height) ratio (WSR) is a good marker of MS in adults and children and may become a simple parameter to predict the clustering of MS components in subjects at risk.
\end{abstract}

Aim: To determine whether higher values of WSR are associated with the progressive aggregation of MS components among Chilean school-aged children.

Methods and Results: Cross-sectional study in 618 children from urban Santiago. Weight, height, waist circumference, systolic and diastolic blood pressure, and fasting lipid profile and glycemia were determined. Diagnosis of MS was based on the presence of 3 or more out of 5 components of MS defined by Cook et al. (increased waist circumference and blood pressure, hypertriglyceridemia, low HDL cholesterol and hyperglycemia). ROC curves and proportional odds were used to analyze the relationships between WSR and MS and its components.

Mean age of the children was $11 \pm 2$ years old, $52 \%$ female. MS prevalence was $15 \%$. Mean WSR was $0.53 \pm 0.1$. The best WSR cutoff to diagnose MS was $0.55(72 \%$ sensitivity and $70 \%$ specificity). Using a proportional odds model, for each 0.01 increment in WSR, the OR of increasing one or more component of the MS was 1.27 (IC 95\%: 1.22-1.32).

Conclusion: The increase in WSR predicts the progressive clustering of MS components in children and adolescents. WSR determination is simple and fast and could become a useful marker to identify children and adolescents at risk of developing MS.

Keywords: waist to height ratio, metabolic syndrome, cardiovascular risk, children
Volume 4 Issue I - 2017

Pilar Arnaiz,' Monica Acevedo, ${ }^{2}$ Salesa Barja,' Rodrigo Bancalari, ${ }^{3}$ Gabriel Cavada, ${ }^{3}$ Hernan Garcia,' Giovanna Valentino, ${ }^{2,5}$ Julian Halcox ${ }^{4}$ 'Divisiones de Pediatriay, Chile

2Enfermedades Cardiovasculares, Chile

${ }^{3}$ Escuela de Medicina, Facultad de Medicina, Pontificia

Universidad Catolica de Chile, Chile

${ }^{4}$ Departmentos de Pediatría y Salud Pública, Universidad de Los Andes, Chile

Correspondence: Monica Acevedo M.D, Associate Professor of Medicine, Escuela de Medicina, Facultad de Medicina, Pontificia Universidad Catolica de Chile, Portugal 61, Santiago, Chile, Tel 562 3543334, Fax 562 63252,

Email macevedo@med.puc.cl

Received: July II, 2016 | Published: February 22, 2017
Abbreviations: MS, metabolic syndrome; CV, cardiovascular; WC, waist circumference; HDLC, HDL cholesterol levels; CVD, cardiovascular disease; LDLC, LDL cholesterol; LR, likelihood ratio

\section{Introduction}

The epidemic of obesity in children and adolescents is a global concern. This is an increasing problem in Chile, where the current prevalence of obesity in first year primary school children is around $21 \%{ }^{1}$ This scenario is expected to lead to an increasing prevalence of the metabolic syndrome (MS) in the coming years, with consequent escalating risk of type 2 diabetes and cardiovascular (CV) diseases in adulthood. ${ }^{2,3}$ Data from the USA report a 4 to $9 \%$ prevalence of MS among adolescents in the general population rising to between 38 to $50 \%$ among obese adolescents. ${ }^{4}$ Similar figures have been reported in Chile. ${ }^{5,6}$ Most studies examining the presence of the MS among children and adolescents use the definition of Cook et al., ${ }^{7}$ which considers the presence of three or more of the following components: increased waist circumference (WC), arterial blood pressure (BP), triglyceride levels (TG) and glucose levels, and decreased HDL cholesterol levels (HDLC). According to this definition, if a child has only two components, he/she does not have MS. Importantly, each of MS components has a continuous association with long-term cardiovascular disease (CVD) risk and risk increases in line with the number of abnormal MS variables. Thus, a dichotomous "yes-no" definition of MS cannot provide adequate discrimination of those with and without risk and consequently may not provide a sufficient alert to ongoing lifetime risk if the diagnostic threshold is not quite met, which is fundamental when considering the pediatric population.

Several anthropometric parameters have been used in order to predict the risk of MS and type 2 diabetes. Many studies have shown an increased prevalence of MS and its components with increasing body mass index (BMI). ${ }^{8,9}$ Epidemiological studies in both adults and children have evaluated and validated waist circumference (WC) as an important predictor not only of cardiovascular risk factors, but also of type 2 diabetes and atherosclerosis. ${ }^{10-16} \mathrm{BMI}$ and $\mathrm{WC}$ in children require the use of percentiles according to sex and age, which can be time-consuming and impractical. Furthermore, more muscular children often have BMIs in the higher centile range and taller, largerframed children may have waist circumferences in the higher centile range in the absence of excess adiposity. Therefore, anthropometric measurements, which incorporate waist circumference in relation to the body shape, as does the waist to stature (height) ratio (WSR), could have a greater utility for the prediction of risk factors related to obesity and the distribution of body fat in both children and adults. ${ }^{17-21}$ 
WSR can be easily and rapidly calculated in daily practice in that it does not require comparison to percentile tables. A study in Chilean adults has recently shown that WSR is a more precise predictor of general mortality than BMI. ${ }^{22}$

Because the current definition of MS does not fully quantify the full extent of cardiometabolic risk among children, the present study sought to examine whether increased WSR values are associated with the progressive accumulation of MS components and the strength of any such relationships. Therefore, we determined the proportional risk of aggregation of these components in relation to the increase in WSR among a pediatric population.

\section{Methods}

This cross-sectional study was carried out between October and December 2005 in 618 school children from middle, lowmiddle and low social-economic level from community schools in urban Santiago and children and adolescents seen by primary care providers within the Catholic University Health Network, because of being overweight or obese. These last children had comparable social-economic characteristics to the others, and were included to reach a sample size with enough power to test the hypothesis. We included subjects between 6 and 16 years old and excluded those with personal and/or family history of metabolic disorders such as diabetes, genetic dyslipidemias, and other genetic metabolic diseases. We also excluded children with history of hypothyroidism and those receiving pharmacological therapy. Their responsible adult signed an informed consent form approved by the Ethics Committee of the School of Medicine.

\section{Clinical evaluation}

A team of fully trained pediatricians and nurses determined weight, height; WC and BP. Weight and height were measured with a balance scale and a SECA ${ }^{\circledR}$ stadiometer, with the child shoeless and wearing light clothing. Recorded values were the average of three measurements. BMI was calculated and expressed in percentiles as weight (in $\mathrm{kg}$ ) divided by height (in $\mathrm{m}$ ) squared. Obesity was defined as $\mathrm{BMI} \geq 95^{\text {th }}$ centile, overweight as $85-94^{\text {th }}$ centile $85-94^{\text {th }}$, eutrophia as $10-84^{\text {th }}$ centile and underweight as $<10^{\text {th }}$ centile (CDC-NCHS, year 2000). ${ }^{23} \mathrm{WC}$ was measured with an inextensible metric tape, over the laterosuperior edge of the right iliac crest, at the end of exhaling. Recorded values were the average of three measurements. ${ }^{24}$ The waist to height ratio (WSR) was calculated by dividing waist circumference by height (both in $\mathrm{m}$ ). Arterial blood pressure was measured according to international guidelines. ${ }^{25} \mathrm{We}$ considered pre-hypertension and hypertension with a systolic blood pressure (SBP) and/or diastolic blood pressure (DBP) of $\geq 90$ to $94^{\text {th }}$ and $\geq 95^{\text {th }}$ centile, respectively, according to sex, age and height. ${ }^{25}$

\section{Blood tests}

Blood samples were obtained after a 12-hour fasting. Blood glucose was measured using enzymatic methods (Hexokinase-Hitachi Modular P-Roche); total cholesterol (TC) was measured by colorimetric enzymatic methods-CHOD-PAP (Hitachi Modular P-Roche); HDL cholesterol (HDLC) was determined by the homogenous colorimetric enzymatic method (Hitachi Modular P-Roche) and triglycerides (TG) by the colorimetric enzymatic method with white-glycerol (Hitachi Modular P-Roche). LDL cholesterol (LDLC) was calculated using the Friedewald formula.

\section{Definition of metabolic syndrome}

The recommendation of Cook et al., ${ }^{7}$ Was used for defining MS in children and adolescents. This definition was based on the ATP III criteria for adults, which considers the presence of at least three out of five of the following components: $\mathrm{WC} \geq 90^{\text {th }}$ of the pattern used (age-sex and ethnicity specific percentiles), ${ }^{24} \mathrm{HDLC} \leq 40 \mathrm{mg} / \mathrm{dl}$ (in boys and girls) $\mathrm{TG} \geq 110 \mathrm{mg} / \mathrm{dl},{ }^{26}$ glucose $\geq 100 \mathrm{mg} / \mathrm{dl}$ and SBP and $/$ or $\mathrm{DBP} \geq \mathrm{pc} 90 .{ }^{25}$

\section{Statistical analysis}

Based on the described prevalence of obesity and MS of $20 \%$, with $95 \%$ confidence and an estimated error not greater than $3.5 \%$, the needed sample size calculated to find the necessary number of children with clustering of MS components was 502 children. Here, we are reporting on 618 children. We used mean and standard deviations of the mean (SD) for the descriptive analysis and student t-test for the continuous variables. ANOVA was used to compare means and chisquare test and Fisher's exact test were used for comparing categorical variables.

MS was modeled as a function of $\mathrm{z}$ score WSR and $\mathrm{z}$ score Waist, through logistical regression models ( $\mathrm{z}$ score was used here in order to transform WSR and Waist values in continuous variables, standardized by age and sex). The discriminatory capacity of the model was evaluated using the area below the ROC curve, with the Youden index as the cutoff (sensitivity and specificity of the model), verified by the post-test probability ratio or Likelihood Ratio (LR). The risk of (co) existence of one or more, two or more and three or more MS components was calculated using logistical regression models under the assumption of proportional odds. MQL Fisher scoring was used for estimation. The statistical significance was established at 5\%, CI $95 \%$.

\section{Results}

The mean age of the children was $11 \pm 2$ years old; $52 \%$ of them were female. The prevalence of MS in the entire cohort was $15 \%$ and was similar in boys and girls. Age, anthropometric characteristics, including WSR, and the values of the individual MS components were similar in boys and girls. SBP and glucose were higher in boys, although levels were within normal ranges. Mean WSR was 0.52 (Table 1). WC, SBP, TG, glucose and WSR, were significantly higher and HDL cholesterol was lower in obese compared with eutrophic children of both genders. DBP was higher only in obese girls compared to eutrophic, but without reaching statistical significance (Table 2). Mean levels of the MS components BP, TG, glucose and WC as well as WSR increased with the aggregation of increasing numbers of MS components. Mean HDLC levels fell as the number of MS components increased (Table 3 ).

Using ROC curves, the optimal WSR cutoff point to predict MS turned out to be 0.55 for both sexes, with $72 \%$ sensitivity and $70 \%$ specificity. The positive and negative predictive values were 30 and $94 \%$ respectively. The LR (post-test probability ratio) was 2.5 . The area below the ROC curve was 0.766 .

Figure 1A shows the risk of aggregation of MS components (risk of aggregation of 1 or more, 2 or more or 3 or more risk factors), using a proportional odds model. For each 0.01 increment in WSR, the OR of increasing one or more component of the MS was 1.27 (IC 95\%: 1.22-1.32). As an example, if a boy has a WSR of 0.60 , which is above 
the 0.55 cutoff points, he would approximately have $95 \%$ probability of having 1 or more MS components, $60 \%$ of having 2 or more, and almost $28 \%$ of having 3 or more MS components. The strength of the relationship between WSR and clustering of MS variables did not change after adjustment by age and gender). Using the same proportional odds model, Figure 1B shows the risk of aggregation of 1 or more, 2 or more or 3 or more MS components using the WC (but excluding WC as an MS component). For each 1 centimeter increment in $\mathrm{WC}$, the OR of increasing one or more component of the MS was
1.04 (IC 95\%: 1.03-1.06). Adjustment by age and gender did not change the results.

Given that WC is included as one of the components in the definition of the MS, we proceeded to examine the effect of WSR as a predictor of the clustering of the four non-anthropometric MS variables, having excluded WC from the model (Figure 2). In this case, for every 0.01 increment in WSR, the OR of increasing one component or more of MS was 1.10 (IC 95\%: 1.07-1.14).

Table I Anthropometric and metabolic characteristics

\begin{tabular}{lllllll}
\hline \multirow{2}{*}{ Variable } & \multicolumn{2}{l}{ Boys $(\mathbf{N}=299)$} & \multicolumn{2}{l}{ Girls $(\mathbf{N}=\mathbf{3}$ | 9) } & \multicolumn{2}{l}{ Total $(\mathbf{N}=6$ | 8) } \\
\cline { 2 - 7 } & Mean & SD & Mean & SD & Mean & SD \\
\hline Age (Years) & 11 & 2 & 11 & 2 & 11 & 2 \\
Height $(\mathrm{cm})$ & 146 & 13 & 146 & 11 & 146 & 12 \\
WC $(\mathrm{cm})$ & 78 & 12 & 78 & 12 & 78 & 12 \\
WSR & 0.5 & 0.1 & 0.53 & 0.1 & 0.52 & 0.1 \\
SBP $(\mathrm{mmHg}) *$ & 108 & 12 & 105 & 12 & 107 & 12 \\
DBP $(\mathrm{mmHg})$ & 68 & 10 & 67 & 9 & 67 & 10 \\
HDLC $(\mathrm{mg} / \mathrm{dl})$ & 49 & 13 & 49 & 11 & 49 & 12 \\
TG $(\mathrm{mg} / \mathrm{dl}$ & 93 & 59 & 91 & 42 & 92 & 51 \\
Glucose $(\mathrm{mg} / \mathrm{dl}) *$ & 90 & 7 & 87 & 7 & 89 & 7
\end{tabular}

Abbreviations: WC, waist circumference;WSR, waist to height ratio; SBP, systolic blood pressure; DBP, diastolic blood pressure; HDLC, high-density lipoprotein cholesterol;TG, triglycerides; ${ }^{*} \mathrm{p}<0.05$ boys versus girls.

Table 2 Components of metabolic syndrome and WSR according to sex and nutritional state

\begin{tabular}{|c|c|c|c|c|c|c|c|c|c|c|c|c|}
\hline \multirow{3}{*}{ Variable } & \multicolumn{6}{|l|}{ Boys } & \multicolumn{6}{|l|}{ Girls } \\
\hline & \multicolumn{2}{|c|}{ Eutrophic(N=91) } & \multicolumn{2}{|c|}{ Overweight( $\mathbf{N}=83)$} & \multicolumn{2}{|c|}{ Obese( $\mathbf{N}=124)$} & \multicolumn{2}{|c|}{ Eutrophic(N=97) } & \multicolumn{2}{|c|}{ Overweight(N=95) } & \multicolumn{2}{|c|}{ Obese $(\mathrm{N}=\mid 28)$} \\
\hline & Mean & SD & Mean & SD & Mean & SD & Mean & SD & Mean & SD & Mean & SD \\
\hline$W C(\mathrm{~cm})$ & 68 & 8 & 76 & 9 & 86 & $\mathrm{II} *$ & 67 & 7 & 77 & 7 & 86 & $10 *$ \\
\hline $\begin{array}{l}\text { SBP } \\
(\mathrm{mmHg})\end{array}$ & 105 & II & 106 & II & 112 & $12 *$ & 102 & 10 & 104 & II & 108 & $12 *$ \\
\hline $\begin{array}{l}\text { DBP } \\
(\mathrm{mmHg})\end{array}$ & 65 & 13 & 66 & 9 & 70 & $10 *$ & 65 & 8 & 66 & 10 & 69 & 10 \\
\hline $\begin{array}{l}\text { HDLC } \\
(\mathrm{mg} / \mathrm{dL})\end{array}$ & 56 & 13 & 49 & 12 & 45 & $1 \mathrm{I} *$ & 54 & 12 & 49 & II & 45 & $8 *$ \\
\hline $\begin{array}{l}\text { TG } \\
(\mathrm{mg} / \mathrm{dL})\end{array}$ & 66 & 36 & 86 & 44 & 118 & $71 *$ & 75 & 36 & 94 & 37 & 101 & $48 *$ \\
\hline $\begin{array}{l}\text { Glucose } \\
(\mathrm{mg} / \mathrm{dL})\end{array}$ & 87 & 6 & 91 & 7 & 92 & $7 *$ & 86 & 6 & 88 & 6 & 87 & $8 *$ \\
\hline WSR & 0.5 & 0 & 0.5 & 0 & 0.6 & $0 *$ & 0.5 & 0 & 0.5 & 0 & 0.6 & $0 *$ \\
\hline
\end{tabular}

Abbreviations: WC, waist circumference; SBP, systolic blood pressure; DBP, diastolic blood pressure; HDLC, high density lipoprotein cholesterol; TG, triglycerides;WSR, waist height ratio; ${ }^{\mathrm{p}}<0.05$ (ANOVA, eutrophic versus overweight versus obese). 
Table 3 Mean values of individual MS components and WSR according to the clustering of MS components.

\begin{tabular}{|c|c|c|c|c|c|c|c|c|c|c|c|c|c|}
\hline \multirow{4}{*}{$\begin{array}{l}\text { Components of } \\
\text { MS }\end{array}$} & \multirow{2}{*}{\multicolumn{2}{|c|}{$\begin{array}{l}0 \\
\mathbf{N}(\%)\end{array}$}} & \multicolumn{2}{|l|}{ I } & \multicolumn{2}{|l|}{2} & \multicolumn{2}{|l|}{3} & \multicolumn{2}{|l|}{4} & \multicolumn{2}{|l|}{5} & \multirow{4}{*}{ P for Trend } \\
\hline & & & $\mathbf{N}(\%)$ & & $\mathbf{N}(\%)$ & & $\mathbf{N}(\%)$ & & $\mathbf{N}(\%)$ & & $\mathbf{N}(\%)$ & & \\
\hline & \multicolumn{2}{|c|}{$204(33)$} & \multicolumn{2}{|c|}{$199(32)$} & \multicolumn{2}{|c|}{120 (19) } & \multicolumn{2}{|c|}{69 (II) } & \multicolumn{2}{|l|}{$22(4)$} & \multicolumn{2}{|l|}{$4(1)$} & \\
\hline & Mean & SD & Mean & SD & Mean & SD & Mean & SD & Mean & SD & Mean & SD & \\
\hline$W C(\mathrm{~cm})$ & 70 & 7 & 75 & 8 & 81 & 9 & 84 & 10 & 90 & 8 & 92 & 17 & $*$ \\
\hline $\mathrm{SBP}(\mathrm{mmHg})$ & 102 & 9 & 106 & $\mathrm{II}$ & 108 & 12 & 114 & 12 & 121 & 8 & 124 & 13 & $*$ \\
\hline $\mathrm{DBP}(\mathrm{mmHg})$ & 63 & 7 & 66 & 10 & 70 & 9 & 71 & 11 & 74 & 9 & 74 & 15 & $*$ \\
\hline HDLC (mg/dL) & 56 & 10 & 50 & $\mathrm{II}$ & 45 & 10 & 39 & 8 & 36 & 8 & 34 & 5 & $*$ \\
\hline TG (mg/dL) & 63 & 22 & 82 & 35 & III & 45 & 142 & 64 & 172.9 & 84 & 190 & 44 & $*$ \\
\hline Glucose (mg/dL) & 86 & 6 & 89 & 6 & 90 & 8 & 91 & 7 & 91.1 & 7 & 105 & 4 & $*$ \\
\hline WSR & 0.48 & 0.04 & 0.52 & 0.05 & 0.56 & 0.05 & 0.57 & 0.06 & 0.6 & 0.05 & 0.63 & 0.04 & $*$ \\
\hline
\end{tabular}

Abbreviations: WC, waist circumference; SBP, systolic arterial pressure; DBP, diastolic arterial pressure; HDLC, high density lipoprotein cholesterol; TG, triglycerides; WSR, waist height ratio; ${ }^{*} \mathrm{p}<0.05$

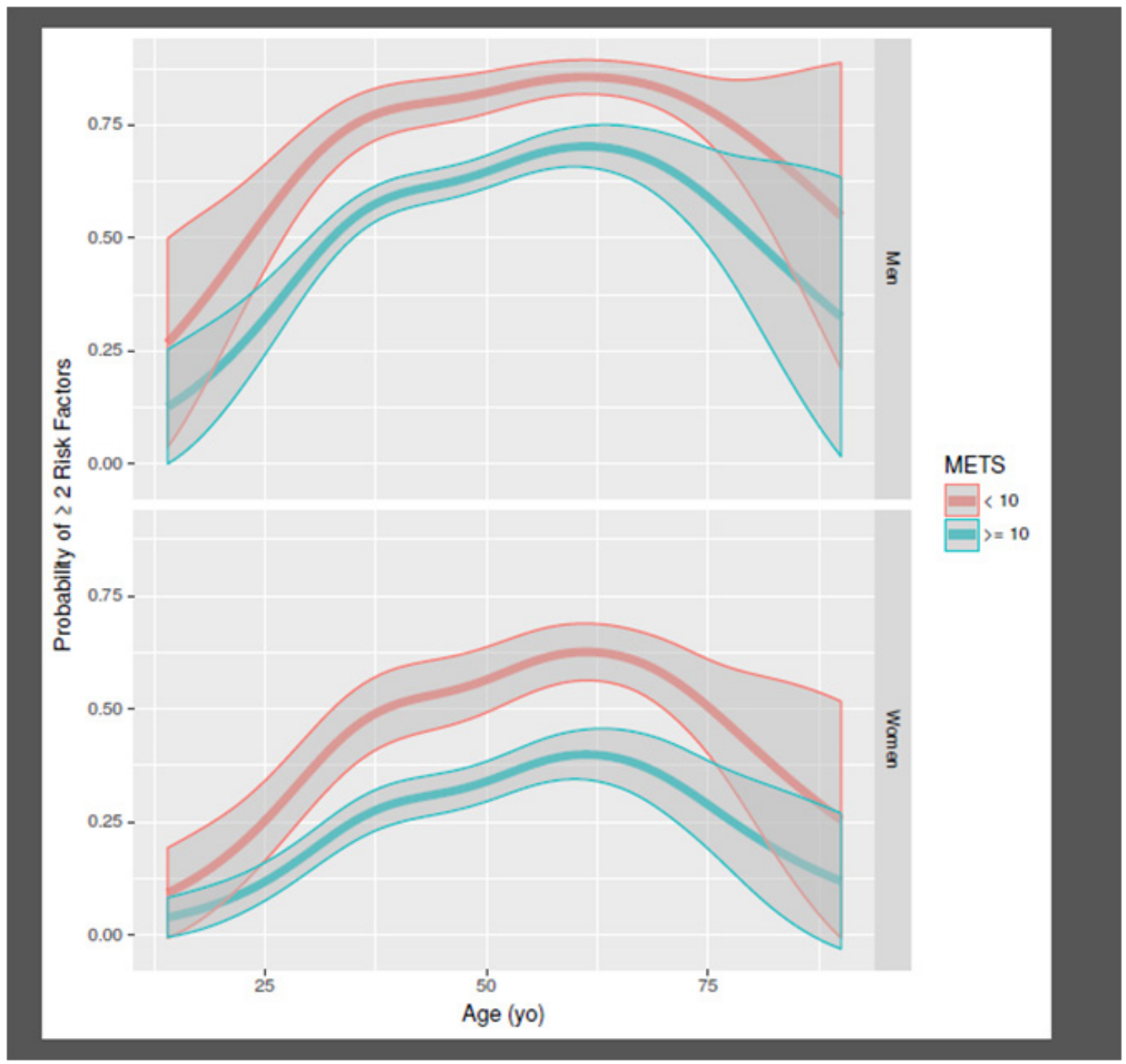

Figure I Risk of presenting I or more, 2 or more or 3 or more MS components of the Metabolic Syndrome using z score Waist to Stature Ratio (panel A) and z score Waist Circumference (panel B). 


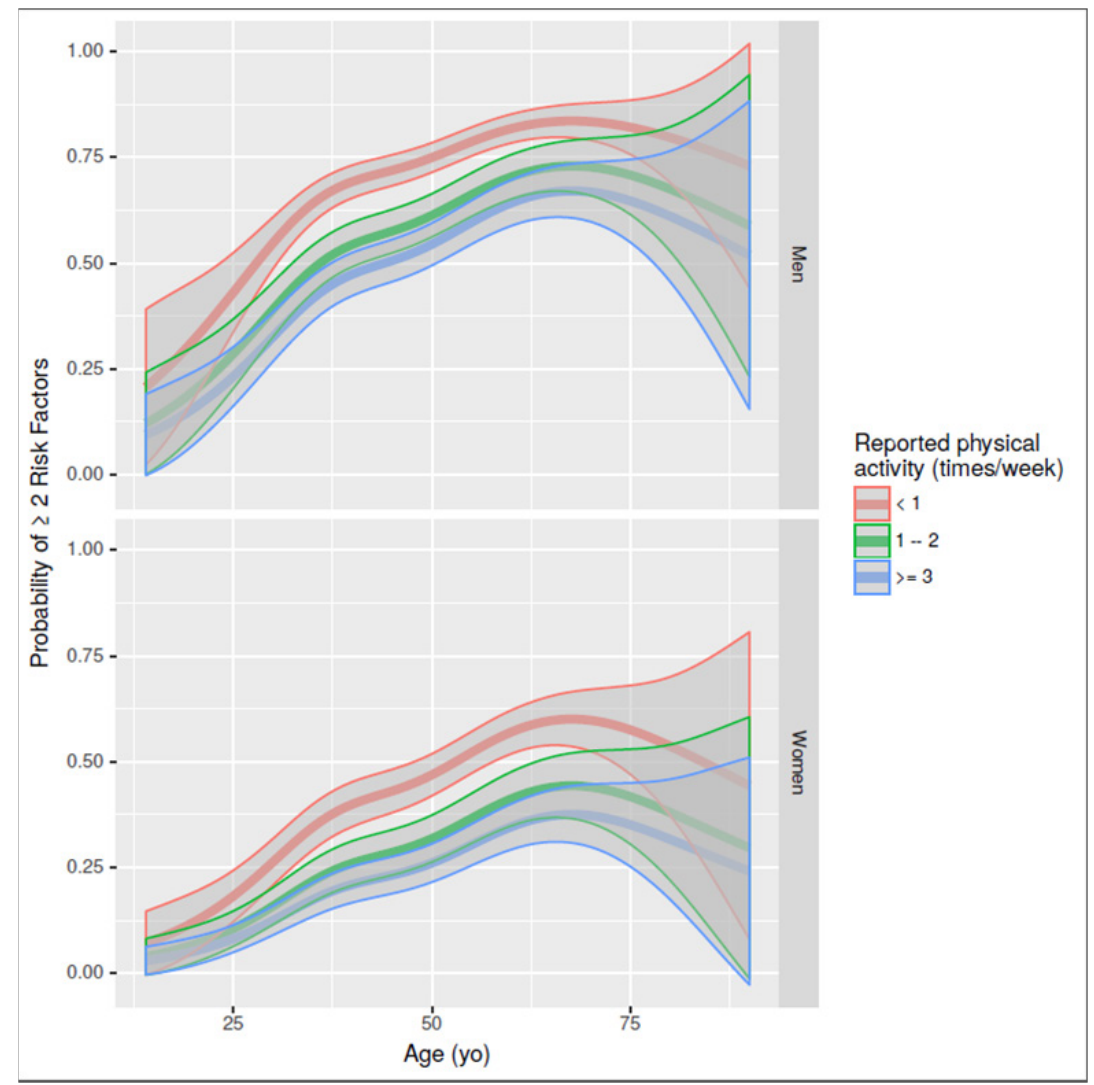

Figure 2 Risk of presenting I or more, 2 or more or 3 or more MS components of the Metabolic Syndrome using z score Waist to Height Ratio (WSR), but excluding WC as an MS component.

\section{Discussion}

Our results demonstrate that the increase in WSR predicts the progressive clustering of MS components in children and adolescents. WSR can be assessed quickly and easily. This has the potential to become a practical and useful anthropometric marker to identify children and adolescents most likely to developing an aggregation of cardiometabolic risk factors that place them at a higher risk of developing not only diabetes but also premature atherosclerotic disease later in their lives. ${ }^{3,27}$

Our results also emphasize the concept of the accumulation of MS components might be more relevant, from a long-term riskprediction perspective, than the contemporary dichotomous ("yesno") definition applied today with MS.7 In pediatrics, this vision of the cardiometabolic risk is very important, considering most children in our cohort (84\%) did not present with 3 or more components and obtain a diagnosis of MS. Indeed, over half of our cohort had 1 or 2 components $(51 \%)$ and are almost certainly already at risk making them candidates for intensive lifestyle intervention in an attempt to reverse the frequent progression to more advanced metabolic dysfunction and premature CVD.

The epidemic of overweight and obesity in childhood, with its important influence on metabolism and the circulatory system, has encouraged investigators to look for novel biochemical, anthropometric and imaging risk markers that could be used in children as well as in adults to predict later cardiovascular or diabetes risk [28-31]. For this reason, it would be very useful to establish the utility of the more promising of these new markers in children. The key requirements of such a marker are that they should be easy and fast to measure, standardisable and with good repeatability and reproducibility. The principle current markers are BMI and WC which have proven ability to predict MS in children. ${ }^{20,21,32}$ However, WSR has the "unique" ability to standardize the waist circumference of the child against their height taking into account the overall size of the child in a way that the centile charts, which have to be selected by age and gender, cannot. This may also be a more appropriate way than the traditional centilebased approach to account for the ethnic origin of the child. ${ }^{17}$ Indeed, the Bogalusa Study investigators have found a similar predictive ability of BMI-for-age and WSR to identify children with adverse risk factors, concluding that WSR would be the preferred marker for its simplicity. ${ }^{20}$ They also found, in a follow-up study conducted two years later, that among overweight children, WSR values were more strongly associated with adverse risk-factor levels than levels of BMIfor-age or skinfold thickness. ${ }^{32}$ Clearly, additional information will be needed to demonstrate the relationship between childhood WSR and onset of clinical disease in adulthood.$^{32}$ However, the potential value of such an approach has been demonstrated in a recent Chilean study, which found that WSR is a better predictor of all-cause mortality than BMI or waist-to-hip ratio in adults. ${ }^{22}$

Our study emphasizes the importance of identifying children with aggregation of 1 or 2 risk factors in association with central adiposity. These individuals are already at higher risk of developing the MS and are likely to benefit from timely intervention with intensive diet and exercise programs to revert this tendency rather than waiting for them to develop the more advanced diagnosis of MS with 3 or more risk factors as defined by Cook et al [7]. By proposing a dynamic instead 
of a static model (Figure 1). We are able to demonstrate a child's risk of having 1 or "more" or 2 or "more" and 3 or "more" risk factors according to their WSR. We believe that this is a novel and important consideration to improve the identification of children at increased long-term cardiometabolic risk. We therefore believe that WSR can be considered a functional "bedside" marker, being easy to apply in the ambulatory setting and simple to calculate without the need for use of tables and percentiles, as with BMI and WC.

\section{Our study has limitations}

Firstly, in the model we have used for MS prediction WSR incorporates the $\mathrm{WC}$ in the calculation of the ratio which introduces potential bias as WC is a component of MS. However, we have also clearly demonstrated in a further model that WSR was also predictive of the non-anthropometric cardio-metabolic risk factors that comprise the MS (Figure 2). Secondly, ours is a cross-sectional study that has estimated associations between variables and has not examined these relationships prospectively, which would likely provide more robust causal inferences. Nonetheless, the long-term impact of cardiometabolic risk factors in childhood and adulthood is becoming increasingly well understood and it is likely that anthropometric measures that improve identification of young individuals with these risk factors, such as WSR, will be useful for long-term risk prediction and management. Likewise, our sample presented a relatively narrow age range predominantly between $10-14$ years and was conducted in an urban population of Chilean children. Further work will be required to examine these relationships in other age groups and in other distinct populations of children before the results can be applied more widely in management of cardiometabolic risk in childhood. Finally, we did not adjust the results by pubertal stage which might also influence the model.

In conclusion, increasing WSR predicts the progressive aggregation of MS components among children. Measurement of WSR is simple, quick and practical and has the potential to enhance identification and follow-up of children with increased cardio-metabolic risk in susceptible populations.

\section{Acknowledgments}

None.

\section{Conflicts of interest}

The author declares there is no conflict of interest.

\section{References}

1. Junae (2008) Situación nutricional de los escolares de primero básico. Disponible.

2. Gami AS, Witt BJ, Howard DE, et al. Metabolic syndrome and risk of incident cardiovascular events and death: A systematic review and meta-analysis of longitudinal studies. $\mathrm{J} \mathrm{Am} \mathrm{Coll} \mathrm{Cardiol.}$ 2007;49(4):403-414.

3. Morrison JA, Friedman LA, Wang P, et al. Metabolic syndrome in childhood predicts adult metabolic syndrome and type 2 diabetes mellitus 25 to 30 years later. J Pediatr. 2008;152(2):201-206.

4. Weiss R, Dziura J, Burgert TS, et al. Obesity and the metabolic syndrome in children and adolescents. NEngl JMed. 2004;350(23):23622374.

5. Barja S, Arteaga A, Acosta AM, et al. Insulin resistance and other expressions of metabolic syndrome in obese Chilean children. Rev Med Chil. 2003;131(3):259-268.
6. Burrows R, Burgueno M, Leiva L, et al. Cardiovascular risk and metabolic profile in obese children and adolescents with low insulin sensitivity]. Rev Med Chil. 2005;133(7):795-804.

7. Cook S, Weitzman M, Auinger P, et al. Prevalence of a metabolic syndrome phenotype in adolescents: Findings from the third national health and nutrition examination survey, 1988-1994. Arch Pediatr Adolesc Med. 2003;157(8):821-827.

8. Daniels SR, Morrison JA, Sprecher DL, et al. Association of body fat distribution and cardiovascular risk factors in children and adolescents. Circulation. 1999;99(4):541-545.

9. Ervin RB. Prevalence of metabolic syndrome among adults 20 years of age and over, by sex, age, race and ethnicity, and body mass index: United states, 2003-2006. Natl Health Stat Report. 2009;(13):1-7.

10. Lee CM, Huxley RR, Wildman RP, et al. Indices of abdominal obesity are better discriminators of cardiovascular risk factors than BMI: A meta-analysis. J Clin Epidemiol. 2008;61(7):646-653.

11. Lee S, Bacha F, Gungor N, et al. Waist circumference is an independent predictor of insulin resistance in black and white youths. $J$ Pediatr. 2006;148(2):188-194.

12. Katzmarzyk PT, Srinivasan SR, Chen W, et al. Body mass index, waist circumference, and clustering of cardiovascular disease risk factors in a biracial sample of children and adolescents. Pediatrics. 2004;114(2):e198-e205.

13. Messiah SE, Arheart KL, Lipshultz SE, et al. Body mass index, waist circumference, and cardiovascular risk factors in adolescents. J Pediatr 153(6): 845-850.

14. Gelber RP, Gaziano JM, Orav EJ, Manson JE, Buring JE, et al. (2008) Measures of obesity and cardiovascular risk among men and women. J Am Coll Cardiol. 2008;52(8):605-615.

15. Klein S, Allison DB, Heymsfield SB, et al. Waist circumference and cardiometabolic risk: A consensus statement from shaping America's health: Association for weight management and obesity prevention; naaso, the obesity society; the American society for nutrition; and the American diabetes association. Am J Clin Nutr. 2007;85(5):11971202.

16. Wang Y, Rimm EB, Stampfer MJ, et al. Comparison of abdominal adiposity and overall obesity in predicting risk of type 2 diabetes among men. Am J Clin Nutr. 2005;81(3):555-563.

17. Hara M, Saitou E, Iwata F, et al. Waist-to-height ratio is the best predictor of cardiovascular disease risk factors in Japanese schoolchildren. J Atheroscler Thromb. 2002;9(3):127-132.

18. Kahn HS, Imperatore G, Cheng YJ. A population-based comparison of BMI percentiles and waist-to-height ratio for identifying cardiovascular risk in youth. J Pediatr. 2005;146(4):482-488.

19. Panagiotakos DB, Chrysohoou C, Pitsavos C, et al. Hierarchical analysis of anthropometric indices in the prediction of 5-year incidence of hypertension in apparently healthy adults: The ATTICA study. Atherosclerosis. 2009;206(1):314-320.

20. Freedman DS, Kahn HS, Mei Z, et al. Relation of body mass index and waist-to-height ratio to cardiovascular disease risk factors in children and adolescents: The Bogalusa heart study. Am J Clin Nutr. 2007;86(1):33-40.

21. Maffeis C, Banzato C, Talamini G. Waist-to-height ratio, a useful index to identify high metabolic risk in overweight children. $J$ Pediatr. 2008;152(2):207-213.

22. Koch E, Díaz C, Romero T, et al. Razón cintura-estatura como un predictor de mortalidad en población chilena: Un estudio de 8 años de seguimiento en la cohorte del proyecto san francisco. Rev Chil Cardiol. 2007;26(4):145-150. 
23. CDC. CDC Growth Charts. Center for disease control, USA, 2000.

24. Fernandez JR, Redden DT, Pietrobelli A, et al. Waist circumference percentiles in nationally representative samples of African-American, European-American, and Mexican-American children and adolescents. J Pediatr. 2004;145(4):439-444.

25. National High Blood Pressure Education Program Working Group on High Blood Pressure in Children and Adolescents. The fourth report on the diagnosis, evaluation, and treatment of high blood pressure in children and adolescents. Pediatrics. 2004;114(2 Suppl $4^{\text {th }}$ Report):555-576.

26. National cholesterol education program (NCEP): report of the expert panel on blood cholesterol levels in children and adolescents. Pediatrics. 1991;89(3):495-501.

27. Morrison JA, Friedman LA, Gray-McGuire C. Metabolic syndrome in childhood predicts adult cardiovascular disease 25 years later: The Princeton lipid research clinics follow-up study. Pediatrics. 2007;120(2):340-345.
28. Acevedo M, Arnaiz P, Barja S, et al. [relationship of C-reactive protein to adiposity, cardiovascular risk factors and subclinical atherosclerosis in healthy children]. Rev Esp Cardiol. 2007;60(10):10511058.

29. Arnaiz P, Acevedo M, Barja S, et al. (2010) Adiponectin levels, cardiometabolic risk factors and markers of subclinical atherosclerosis in children. Int J Cardiol. 2010;138(2):138-144.

30. Arnaiz P, Acevedo M, Barja S, et al. Arteriosesclerosis subclínica, factores de riesgo cardiovascular clásicos y emergentes en niños obesos chilenos. Rev Chil Ped. 2007;78:135-142.

31. Urbina EM, Williams RV, Alpert BS, et al. Noninvasive assessment of subclinical atherosclerosis in children and adolescents: Recommendations for standard assessment for clinical research: A scientific statement from the American heart association. Hypertension. 2009;54(5):919-950.

32. Freedman DS, Dietz WH, Srinivasan SR, et al. Risk factors and adult body mass index among overweight children: The Bogalusa heart study. Pediatrics. 2009;123(3):750-757. 